\title{
Early Detection of Diseases And Abnormalities In The Respiratory System Using Certainty Factor Method
}

\author{
Mohammad Arman Prambudi ${ }^{1}$, Achmad Muchayan ${ }^{2}$ \\ Faculty of Computer Science, Narotama University, Indonesia \\ armanprambudi02@gmail.com
}

\begin{abstract}
Health is a very important factor in the human body. If the health of ourselves is interrupted, it is also interrupted by someone to do the activity. There are several diseases that have a lot of sufferers. One of them is the disease of the respiratory system. Respiratory system is defined generally as a matter that disrupts the process of breathing in our body. Diseases of the respiratory system is one of the main problems of public health in Indonesia, because the disease is a human breathing. The expert system is a library of specialists or an expert in diseases of the respiratory system and the conditions used to take the conclusion of the symptoms. In the calculation process used the certanity factor method to find a percentage level of confidence. The Parameter used in the diagnosis is the symptom chosen by the sufferer. The conclusion of this application results in the diagnosis of the disease suffered and the percentage result of confidence through the selected symptoms.
\end{abstract}

Keywords: Respiratory disease, expert system, Certainty Factor

\section{INTRODUCTION}

If observed daily life in society, apparently not only educational, economic, and cultural factors are a big problem for society today. Social \& health factors are also a much more important problem to note because the welfare of life has a huge impact on the level of health in the community itself. Health is a valuable thing for people because anyone can experience health problems. In general our body is very susceptible to germs \& viruses. People are also usually less sensitive to the symptoms of a disease. Limited public knowledge of diseases that attack the respiratory system becomes a problem and makes it difficult for people to predict the disease suffered. In this case the community needs a doctor / expert who can help to diagnose early so that it can take precautions early. To overcome this, a tool is needed that can diagnose a disease in the form of an expert system.

Expert system is a software or computer program that is intended as a provider of advice and tools to help solve problems in certain areas of specialization such as science, mathematical engineering, medicine, education and so on (Turban, E. Aronson and Liang, 2007). The basis of an expert system yairu how to trust the science of an expert / expert into the computer / system and how to make decisions from that knowledge(Gustina and Chandra, 2015). The solution to the problem is to create an application to diagnose the disease based on the symptoms suffered.

Starting from the problem, in this study will make an expert system that is able to diagnose diseases and abnormalities of the respiratory system by looking at the symptoms experienced by a person. This expert system is also useful to help the public to know, understand how much certainty is affected by respiratory system diseases. This expert system application can also find out the treatment of first aid in someone who is experiencing the disease.

The expert system that will be created in this study uses the Certainty Factor method to determine the certainty value of the disease by calculating the weight value of symptoms in the disease. Expert systems will be made based on Android, because nowadays people are familiar with smartphones, almost everyone has smartphones ranging from children to adults and smartphones are very often used to find information rather than using a PC or laptop. The system will produce output in the form of a diagnosis of a disease experienced by a person, symptoms that have been selected by the user, and provide solutions for how to prevent disease first aid disease based on the input symptoms that are brought. logged out by the user.

There are several related studies on expert systems to diagnose diseases of the respiratory system and with different solutions. Among them was research conducted by Nur Aini, Ramadiani, Heliza Rahmania Hatta in 2017. This research built an expert system that specifically identifies tuberculosis. In this system will receive 
input in the form of symptoms. This research involved an expert, namely Mr. Eko Haryanto, A.md.Kep. After testing the validation of this study, it produced a web-based expert system with an accuracy rate of $85 \%$. (Aini, Ramadiani and Hatta, 2017).

Other research related to the expert system was conducted by Anugerah Jaya Aziz Amrullah, Ekojono in 2017. his research used forward chaining method to diagnose diseases in the lungs based on symptoms. The process of testing the system of a lung disease diagnosis expert is to compare manual calculations, system calculations, and from an expert who will later produce the accuracy of the system. This study resulted in $86.66 \%$ accuracy of disease diagnosis and 13.34\% error from 15x testing (Aziz Amrullah and Ekojono, 2017) .

Other research has also been conducted by Samsudin (2017) in his research using Case-Based Reasoning method to diagnose Respiratory System Disease. Case-Based Reasoning method applies 4 stages of process, namely retrieve, reuse, revise, and retain. This research uses waterfall model in system development. This research generated a confidence level of up to 85\% (Sadek and Usman, 2017).

The difference of this research to previous research is that previous research only examined one disease in the respiratory system, there is also the same discuss about respiratory system diseases but use different methods in this study.

\subsection{Respiratory System Diseases}

The human respiratory tract starts from the mouth and nose, then unites in the neck area to form the trachea (throat) which will enter the lungs (Raji et al. , 2017). In the lungs, one tracheal airway will be bifurcated, one to the left lung and one to the right lung. After that, each of them will branch again, the longer it will get smaller, 23 times and ends in the alveoli, where gas exchange, oxygen (O2) enters the blood vessels, and carbon dioxide (Muttaqin, 2015). In general, the process of respiration / respiration requires three submit organs, namely the upper airway, lower airway, and gas exchange units (Harison and Kardo, 2017). Respiratory tract disease in general can be defined as something that interferes with the respiratory process in our body.

\subsection{Expert System}

An expert system is a computer system or program that is intended as a provider of advice and aids in solving problems in certain specialties such as science, mathematics engineering, medicine, education and so on (Turban, E. Aronson and Liang, 2007). Expert systems are part of artificial intelligence to solve complex and rigid problems, so that systems are designed not based on analysis and design from the developer, but according to expert knowledge (Agarwal and Goel, 2014). The following is the structure of the expert system shown in Figure 1.

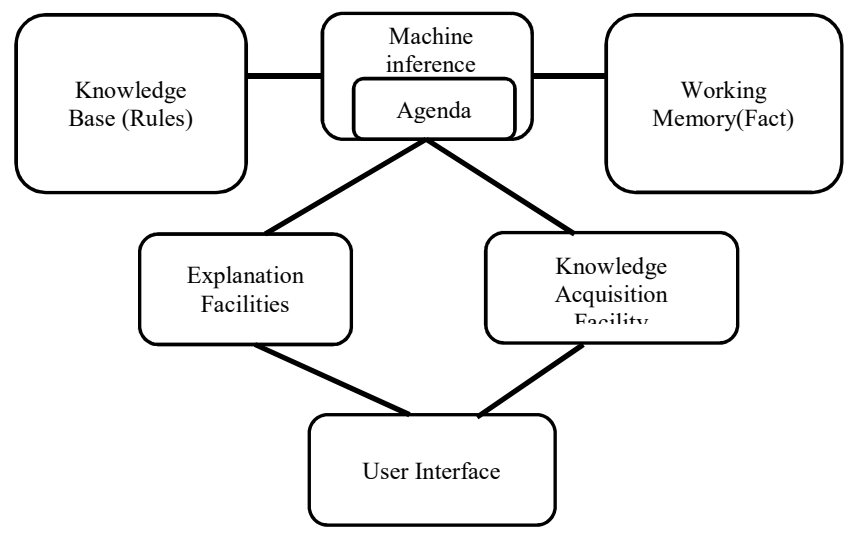

Figure 1. Expert system structure

Components contained in the expert system structure according to figure 2.1 include knowledge base (rule), engine inference, working memory, explanation facility, knowledge acquisition facility, user interface.

The knowledge base itself is dynamic can develop over time. Inference machine is the brain of an expert system known also as control structure or rule interpreter. The inference engine provides a methodology for reasoning information on a knowledge base and on working memory, as well as to formulate conclusions. Working memory is part of an expert system that stores facts obtained during the consultation process. The 
explanation facility is the process of determining the decision during the consultation session. The explanation facility can provide information to the user about the course of reasoning so as to produce a decision of the existing problem. Knowledge acquisition is the process of gathering, transfering, and transforming expertise or expertise to solve problems that come from various sources of knowledge and are poured in an understandable form of the system. User interface as a support for users in the system and also to communicate between the system and the user. The most important thing in creating a interface is the ease of running the system. The interface must be interactive, communicative, and user-friendly.

\subsection{Certainty Factor}

Certainty factor is one method of proving whether a fact is certain or uncertain in the form of metrics commonly used in expert systems (Turban, E. Aronson and Liang, 2007). Certainty factor was first proposed by Shortliffe and Buchanan in 1975 to accommodatethe uncertainty of inexact reasoning ofan expert. An expert /Doctor often analyzes information with expressions such as: possible, likely, large, almost certain (Fauz Rohman, Harsani and Qur, 2016). Certainty Factor expressesconfidence in an event (or fact or hypothesis) based on expert evidence or assessment (Adji, R and Permanasari, 2015). Certainty factor introduces the concept of belief and uncertainty which is then formulated into the basic formulation as follows :

$$
\mathrm{CF}(\mathrm{P}, \mathrm{E})=\mathrm{MB}(\mathrm{P}, \mathrm{E})-\mathrm{MD}(\mathrm{P}, \mathrm{E})(1)
$$

\section{CF : $\quad$ Certainty Factor}

$M B$ : a measure of confidence

$M D$ : a measure of distrust of

in the evidence $\mathrm{H}$ hypothesis given by evidence $\mathrm{E}$ (between 0 to 1 )

$\mathrm{H}:$ Hypothesis

E : Evidence

the hypothesis of evidence $\mathrm{H}$ given evidence $\mathrm{E}$ (between 0 to 1 )

The basic form of formula certainty factor a rule if $\mathrm{E}$ then $\mathrm{H}$ is as intended by equation 2 below:

$$
C F(H, e)=\mathrm{CF}(\mathrm{E}, \mathrm{e}) * \mathrm{CF}(\mathrm{H}, \mathrm{E})=\mathrm{CF}(\text { user }) * \mathrm{CF}(\text { pakar })
$$

$\mathrm{CF}(\mathrm{E}, \mathrm{e})$ : Certainty Factor evidence $\mathrm{E}$ influenced by evidence e

$\mathrm{CF}(\mathrm{H}, \mathrm{e})$ : $\quad$ certainty factor hypothesis influenced by evidence e.

$\mathrm{CF}(\mathrm{H}, \mathrm{E})$ : $\quad$ certainty factor hypothesis assuming evidence is known with certainty, i.e. when $\mathrm{CF}(\mathrm{E}, \mathrm{e})=1$.

If all the evidence in the antecedent is known with certainty then the equation will be:

$$
C F(E, e)=C F(H, E)
$$

In its application, $\mathrm{CF}(\mathrm{H}, \mathrm{E})$ is the value of certainty given by experts to a rule, while $\mathrm{CF}(\mathrm{E}, \mathrm{e})$ is the value of trust given by the user to the symptoms. .

\section{REASERCH METHOD}

Methodology research conducted through stages ranging from problem formulation to conclusions that form a systematic flow with the development model RAD (Rapid Application Development), namely Requirements Plannig Phase, User Design Phase, Construction Phase, Cotuver Phase (Davis et al. , 2020) . The following flow of rad model research stage is found in Figure 2.1. 


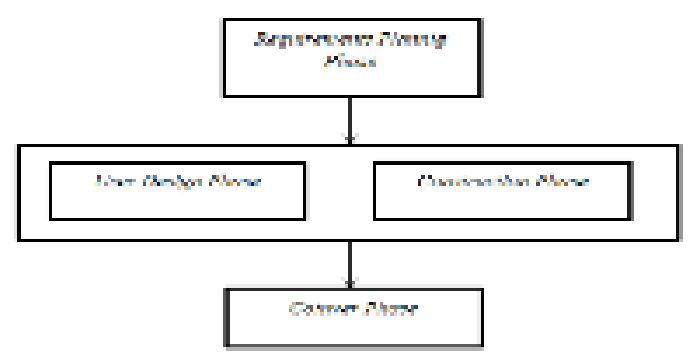

Figure 2.1. RAD (Rapid Application Development) development model

1. Data collection(Requirements Plannig Phase).

Data collection is the process of collecting data or materials for research to be done. In this process the data source is obtained from litelatur studies from several studies that have been done.

2. Design sitstem design (User Design Phase).

System design is a stage of system development into the form of design used to make it easier for users to understand the system to be created.

3. Construction Phase

The development of the system in this research uses certainty factor method. Where this method is used to measure the prosentese level of disease certainty of the system to be made. Here is the calculation of certainty factor method of data collection that has been done.

4. System testing

Testing the system using the Black Box Testing method. Black box testing is a fundamental aspect test that is done by observing the execution results through trials and examining every function of the system created.

\subsection{Data collection}

The first stage of this study was to collect data related to diseases in the respiratory system containing diagnosis and symptom data. this data was obtained through interviews with a doctor / expert and litelatur studies. The results of data collection can be seen in the following table.

Table 1. Respiratory System Disease Symptom Data

\begin{tabular}{|c|l|}
\hline No & Disease Name \\
\hline 1. & ISPA \\
\hline 2. & Tuberculosis \\
\hline 3. & Asthma \\
\hline 4. & Bronchitis \\
\hline
\end{tabular}

Table 2. Respiratory System Disease Symptom Data

\begin{tabular}{|l|c|}
\hline \multicolumn{1}{|c|}{ Symptoms } & $\begin{array}{c}\text { Weig } \\
\text { hts }\end{array}$ \\
\hline [ G1 ] yes, I'm sorry. High fever & 0.5 \\
\hline $\begin{array}{l}\text { [ G2 ] yes, I'm sorry. Decreased } \\
\text { consciousness }\end{array}$ & 0.2 \\
\hline $\begin{array}{l}\text { [ G3 ] yes, I'm sorry. Breathing sounds } \\
\text { loud }\end{array}$ & 0.9 \\
\hline [ G4 ] Restless & 0.2 \\
\hline $\begin{array}{l}\text { [ G5 ] yes, I'm sorry. Lips and skin turn } \\
\text { blue }\end{array}$ & 0.2 \\
\hline [ G6 ] Red patches resembling measles & 0.5 \\
\hline
\end{tabular}


The table above

\begin{tabular}{|l|c|}
\hline [ G7 ] Ear pain expels blood & 0.9 \\
\hline [ G8 ] Breathing squeaks & 0.5 \\
\hline [ G9 ] Cough > 3weeks & 0.5 \\
\hline [ G10 ] Coughing with a cough & 0.2 \\
\hline [G11] Phlegm found blood spots & 0.9 \\
\hline [ G12 ] Shortness of breath & 0.5 \\
\hline [ G13 ] Fever for a month & 0.9 \\
\hline [ G14 ] Night sweats & 0.2 \\
\hline [ G15 ] Reduced appetite & 0.5 \\
\hline [ G16 ] Weight loss menutun & 0.5 \\
\hline [G17] Wheezing & 0.5 \\
\hline [G18] Shortness of breath & 0.9 \\
\hline [G19] Difficulty Breathing & 0.5 \\
\hline [G20] Limp, Lethargic, powerless body & 0.2 \\
\hline [G21] Cough accompanied by mucus & 0.9 \\
\hline grayish-yellow or green & 0.5 \\
\hline [ G22 ] Sore throat & 0.5 \\
\hline [G23] Snot-nosed or tufted nose & 0.5 \\
\hline [G24] Chest pain or discomfort & 0.5 \\
\hline [ G25 ] Fatigue & 0.2 \\
\hline [ G26 ] Mild fever & \\
\hline
\end{tabular}

disease and symptoms along with weighting the following symptoms of each weight. Explanation of weight indications of each symptom:

- $\quad$ Important symptoms $=0.9$

- $\quad$ Moderate symptoms $=0.5$

- $\quad$ Common symptoms $=0.2$

Weighting user confidence in expert system:

- $\quad$ No. 0

- $\quad$ Not sure $=0.4$

- $\quad$ A little sure $=0.6$

- $\quad$ Pretty sure $=0.9$

- $\quad$ Sure $=0.8$

- $\quad$ Very Sure $=1$

\subsection{System design}

System design is a stage of system development into the form of design used to make it easier for users to understand the system to be created. System design uses UML (Unfied Modeling Language), the following stages of system design include usecase diagram, class diagram, activity diagram, sequence diagram (Rosa A.S, 2011).

\subsection{System Development}


The development of the system in this research uses certainty factor method. Where this method is used to measure the prosentese level of disease certainty of the system to be made. Here is the calculation of certainty factor method from the data collection that has been done in table 2.1 and table 2.2.

User chooses symptoms for example for tuberculosis disease:

[ G9 ] Not sure $=0.4$

[ G10 ] A Little Sure $=0.6$

[G11] Not sure $=0.4$

[ G12 ] Not sure $=0.4$

[ G13 ] Sure $=0.8$

[ G14 ] Not sure $=0.4$

[ G15] Not sure $=0.4$

[ G16] A little sure $=0.6$

Calculating CFuser with CFpakar :

$\mathrm{CF}(\mathrm{H}, \mathrm{E})=\mathrm{CF}($ user $) * \mathrm{CF}$ (pakar)

$\mathrm{CF}(1.1)=0.4 * 0.5=0.2$

$\mathrm{CF}(1.2)=0.6 * 0.2=0.12$

$\mathrm{CF}(1.3)=0.4 * 0.9=0.36$

$\mathrm{CF}(1.4)=0.4 * 0.5=0.2$

$\mathrm{CF}(1.5)=0.8 * 0.9=0.72$

$\mathrm{CF}(1.6)=0.4 * 0.2=0.8$

$\mathrm{CF}(1.7)=0.4 * 0.5=0.2$

$\mathrm{CF}(1.8)=0.4 * 0.5=0.2$

Then combine the $C F$ values of each rule:

CFCOMBINE (CF1,CF2) $=$ CF1 + CF2 $*(1-C F 1)$

CFCOMBINE (CF1.1, CF1.2) $=0.2+0.12 *(1-0.2)=0.2+0.096=0.296$ (CFold)

CFCOMBINE (CFold , CF1.3) $=0.296+0.36 *(1-0.296)=0.549$ (CFold)

CFCOMBINE (CFold , CF1.4) $=0.549+0.2 *(1-0.549)=0.639($ CFold $)$

CFCOMBINE (CFold , CF1.5) $=0.639+0.72 *(1-0.639)=0.899$ (CFold)

CFCOMBINE (CFold , CF1.6) $=0.899+0.8 *(1-0.899)=0.907$ (CFold)

CFCOMBINE (CFold , CF1.7) $=0.907+0.2 *(1-0.907)=0.925$ (CFold)

CFCOMBINE (CFold , CF1.8) $=0.925+0.2 *(1-0.925)=0.9405$ (CFold)

Then calculate the percentage of belief:

CFCOMBINE $* 100 \%=0.9405 * 100 \%=94.05$

Thus it can be concluded that the calculation of certainty factors carried out in the type of tb disease has a system confidence rate of $94.05 \%$.

\section{RESUTLS And DISCUSSION}

\subsection{Designing UML (Unfied Modeling Language)}

The UML method is used to design each process to be performed by thesystem (Haviluddin, 2011). In this system design, there are several UML diagrams that will be used as needed by the system.

\subsubsection{Use Case Diagrams}

In the expert system that is built only involves one main actor namely user. User in this case system user, not system designer. Use Case Diagram in this expert system is contained in Figure 1. 


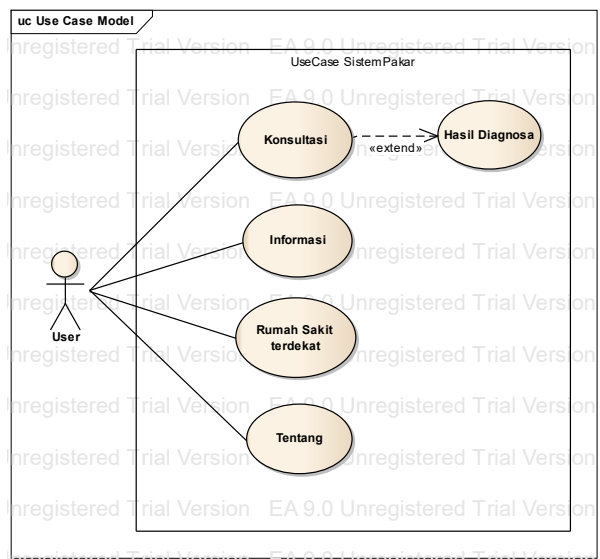

Figure 1. Use Case Diagram Expert System

From Figure 4.1. it looks like the user can do some activities, namely the diagnosis results, looking at the information menu, looking at the nearest sick tumah, looking at the menu about. The process of diagnostic activity is include or part of the consultation menu, therefore the user hasur choose the consultation menu first to answer the questions given by the system correctly, so that the diagnosis results come out.

\subsubsection{Activity Diagram}

In this expert system application there are four activity diagrams namely activity diagram consultation, information, nearest hospital, about. The design of the consultation activity diagram is contained in Figure 2.

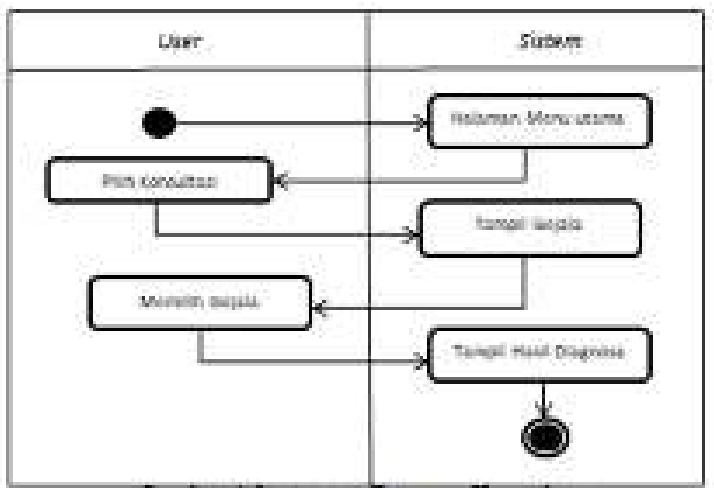

Figure 2. Activity Diagram consultation

In figure 2. explain the user's activities in consulting. User chooses consultation menu on main menu, then system mananpilkan consultation menu, then user conduct consultation by answering questions given by system. After conducting a consultation the system will conduct a diagnostic process to display the results of the diagnosis of the consultation that has been done by the user.

Then activity diagram menu information that shows user activities to see the information menu. Activity diagram menu information is contained in figure 3. 


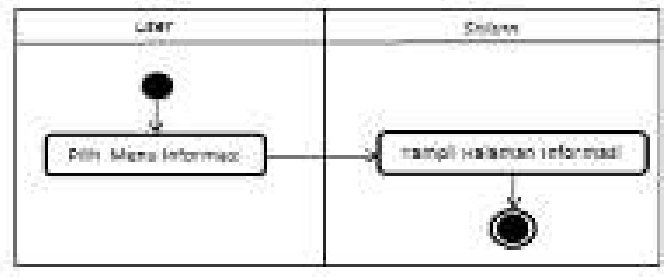

Figure 3. Activity Diagram information menu

Based on Figure 3.3. activities for the information menu page that is the user chooses the information menu through the main page, then the system will display a menu display of information containing information about respiratory diseases and the user chooses the disease that he wants to see. Then the system will display disease information.

Next is the activity diagram of the nearest hospital menu page contained in Figure 4.

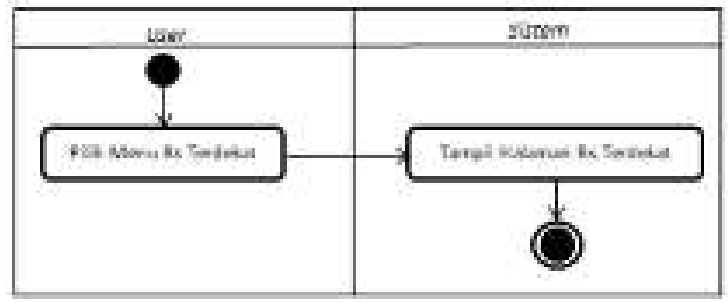

Figure 4. Activity Diagram of nearby hospital menu

Based on the activity flow diagram of the nearest hospital page starting from the user chooses the nearest hospital menu and the system will display maps containing the place / location of the hospital around the user location.

Then activity diagram menu about that shows the user activities to see the menu about. Activity diagram menu about contained in Figure 5.

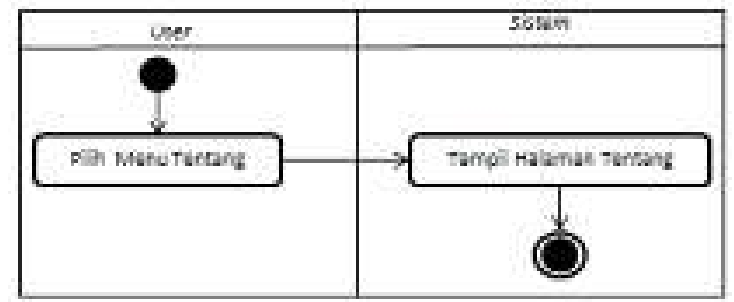

Figure 5. Activity Diagram menu about

Based on the flow activity diagram menu page about starting from the user selecting the menu page about then the system will display information about the expert system.

\subsubsection{Sequence Diagram}

Sequence diagram of consultation menu taken from this expert system. Sequence diagram of consultation menu is found in Figure 6. 


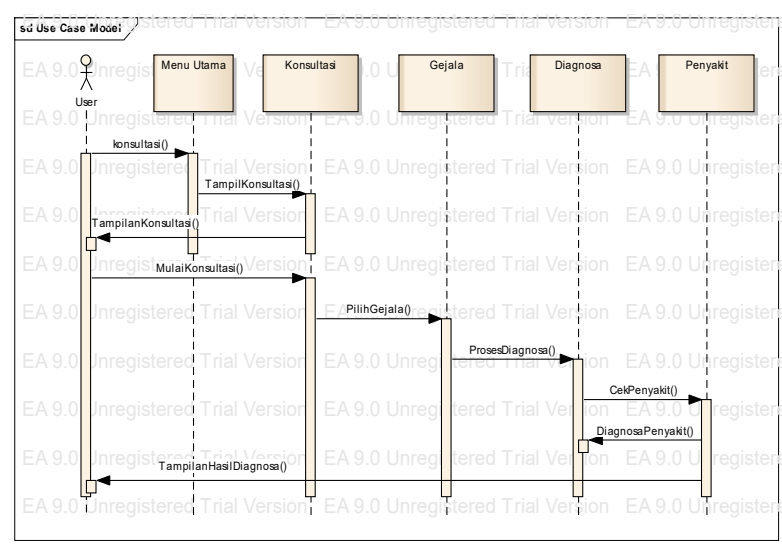

Figure 6. Sequence diagram of consulting menu.

Sequence Diagram in figure 3.6 is assigned from 1 user and 5 objects namely main menu page, consultation menu, symptom form, diagnosis controller, diagnosis result. Here's an explanation of figure 3.6.

1. User accesses the application and enters the main menu

2. Then the User chooses the Consultation menu and display the form of symptoms of the disease.

3. User chooses symptoms from symptom form using Check Box and perform diagnosis process.

4. Then the object of the disease displays the results of the diagnosis of the disease.

\subsubsection{Class Diagram}

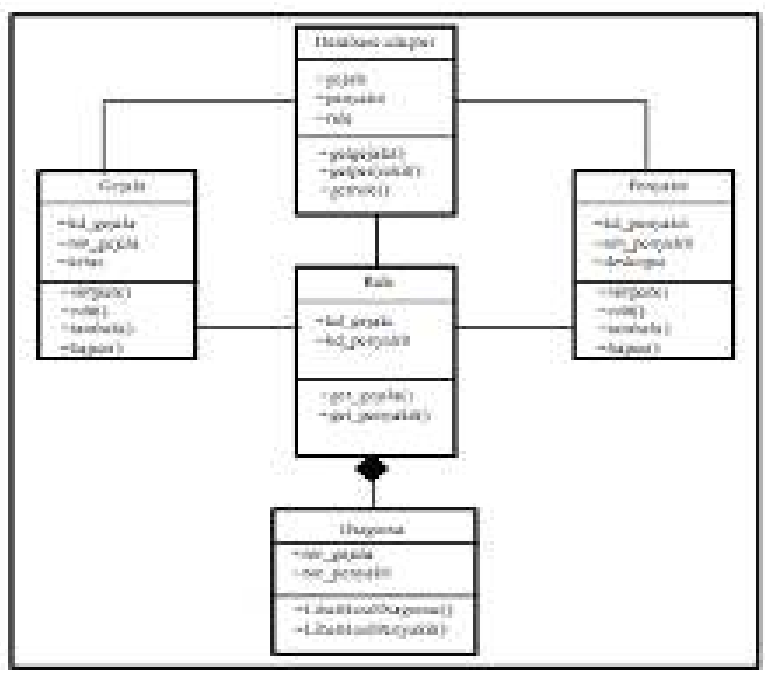

Figure 7. Class diagram consultation.

In Figure 7. explained that the class diagram from the System of Disease Diagnosis Experts in the Respiratory System has 5 classes consisting of Database Adapter, Rule, Symptoms, Disease, Diagnosis.

1. Database Adapter has several classes of derivatives, namely the class of symptoms, diseases, and rules.

2. The symptom class has an association relationship with a rule class that has a cardinality value of one or more. This means one symptom can have one or more relationships.

3. The disease class has an association with the relation class and has only one cardinality value. This means that each disease has only one relationship. While one rule can have one or more diseases.

4. The diagnostic class has a compositional relationship with the rule class. This means the diagnostic class cannot stand in the absence of a rule class. If the class is ruled out then the diagnostic class will also be lost. 


\subsection{System implementation}

At this stage the activities of creating a system or application by using software and hardware in accordance with analilis and design to produce a system. Coding or progran code is how to develop the results of analysis and design that has been done into a system. The system is implemented using Android Studio for processing program code and running applications, java as a programming language. In the implementation of this system first the user will find the main page of the expert system. The results of the implementation of the main menu are contained in Figure 8.

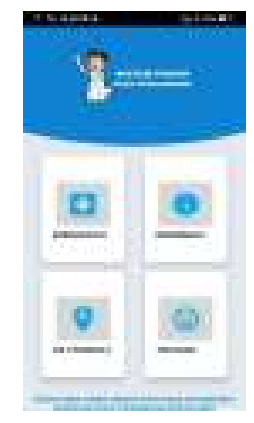

Figure 8. Home Page

In fact, this main thing displays menus such as consultation menu, information, nearest hospital, about. Then enter the implementation to the consultation menu contained in Figure 9.

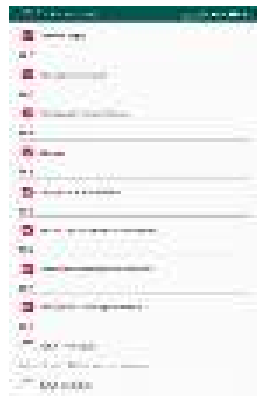

Figure 9. Consultation Menu

In the consultation menu the usercan choose the symptoms given by clicking chek box to select the symptoms. Then the symptoms will be processed and entered into the results of the diagnosis contained in Figure 10.

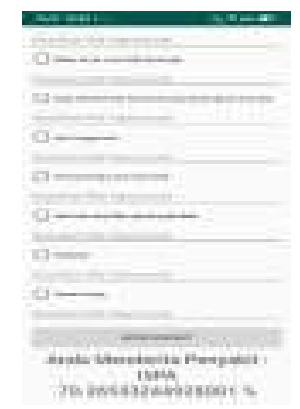

Figure 10. Consultation result menu

In this diagnosis menu the user can see the results obtained from the selected symptoms. In this system take the disease with the largest percentage of ispa disease with a percentage of $70.26 \%$. 
Next it goes on the menu of the nearest hospital. The implementation is contained in Figure 11.

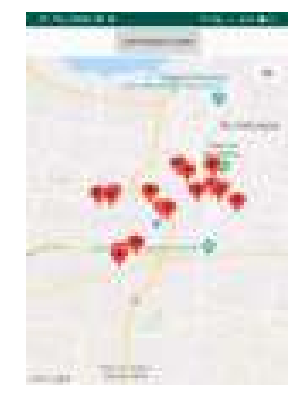

Figure 11. Nearby Hospital Menu

On the nearest Hospital menu the user can find the location of the hospital closest to the location of the user is located, making it easier to find the nearest hospital. Then go to the implementation of the information menu page contained in figure 12 .

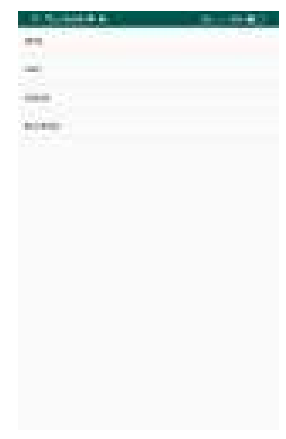

Figure 12. Information Menu

In the information menu the user can see a list of some diseases of the respiratory system and find out information about the disease. Further implementation of the About menu is contained in figure 13.

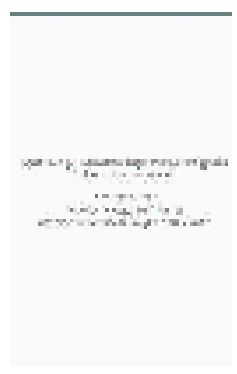

Figure 13. About Menu

In the menu about the user can see information about the system. Like the name of the application, the name of the app creator, emali.

\section{CLOSING}

\subsection{Conslusion}

Based on the analysis, design, and implementation of the system that has been done in the expert system to diagnose early respiratory diseases with android-based certainty factor method, it can be displayed that the application of this expert system can already diagnose early respiratory system disease with certainty factor method based on symptoms entered by the user. In addition to diagnosing respiratory system diseases, the built-in application can also explain information about respiratory diseases and the app can also search for nearby hospitals based on the user's location. This application has been designed using a RAD(Rapid Application 
Development) developmentmodel. With java programming language and using Android Studio software that produces mobile-based applications.

\subsection{Suggestion}

In this study there needs to be some improvement including:

1. Respiratory system diseases discussed not only Ispa disease, Tuberculosis, Asthma, Bronchitis should be supplemented with more respiratory system diseases.

2. Add other symptoms of respiratory system disease.

3. Add in-app features to make it more interesting.

\section{REFRENCE}

Adji, T. B., R, C. P. B. and Permanasari, A. E. (2015) 'Expert System for Diagnosis of Personality Disorders with Certainty Factor Approach', International Conference on Electrical Engineering, Informatics, and Its Education 2015.

Agarwal, M. and Goel, S. (2014) 'Expert system and it's requirement engineering process', in International Conference on Recent Advances and Innovations in Engineering, ICRAIE 2014. doi: 10.1109/ICRAIE.2014.6909306.

Aini, N., Ramadiani, R. and Hatta, H. R. (2017) 'Tuberculosis Diagnosis Expert System', MulawarmanInformatics : Journal of Computer ScienceScientific . doi: 10.30872/jim.v12i1.224.

Aziz Amrullah, A. J. and Ekojono, E. (2017) 'EXPERT SYSTEM FOR DIAGNOSING LUNG DISEASE WITH FORWARD CHAINING METHOD', Jurnal Informatika Polinema. doi: 10.33795/jeep.v2i1.48.

Davis, W. S. et al. (2020) 'Rapid application development (RAD)', in The Information System Consultant's Handbook. doi: 10.1201/9781420049107-32.

Fauz Rohman, I., Harsani, P. and Qur, A. (2016) 'Cow Disease Diagnosis Application Using Android-Based Certainty Factors Method', 84 --Computing, 13(2), pp. 84-93.

Gustina, D. and Chandra, Y. I. (2015) 'Expert System Application to Diagnose Lung Disease In Children Using Rapid Application Development (RAD) Method', Jurnal UMJ, 4(expert system), pp. 1-9. Available at: https://jurnal.umj.ac.id/index.php/semnastek/article/download/522/488.

Harison and Kardo, R. (2017) 'Web-Based Respiratory Disease Diagnosis Expert System Using Forward Chaining Method', MomentumJournal, 19(1), pp. 34-39. doi: 10.21063/JM.2017.V19.1.34-39.

Haviluddin (2011) 'Understanding the Use of UML ( Unified Modelling Language )', Understanding the Use of UML (Unified Modelling Language),6(1), pp. 1-15. Available at: https://informatikamulawarman.files.wordpress.com/2011/10/01-jurnal-informatika-mulawarman-feb2011.pdf.

Muttaqin, A. (2015) Teaching Book of Nursing Clients with Respiratory SystemDisorders, salemba medika.doi: 10.33023/JIKEP. V5I2237.

Raji, A. et al. (2017) 'Respiratory monitoring system for asthma patients based on loT', in Proceedings of 2016 Online International Conference on Green Engineering and Technologies, IC-GET 2016. doi: 10.1109/GET.2016.7916737.

Rosa A.S, and M. S. (2011) Software Engineering Learning Module (Structured and Object Oriented), Bandung: Modula.doi: 10.1017/СВ09781107415324.004.

Sadek, S. and Usman, U. (2017) 'Respiratory Disease Diagnosis Expert System Using Case Based Reasioning Method', Journal of Applied Sciences,11(4), p. 272. doi: 10.22216/jit.2017.v11i3.1034.

Turban, E., E. Aronson, J. and Liang, T.-P. (2007) 'Decision Support Systems and Business Intelligence', Decision Support and Business Intelligence Systems, 7/E. doi: 10.1017/CBO9781107415324.004. 